\title{
Paradoxes of Visibility
}

\author{
László Tarnay \\ University of Pécs (Hungary) \\ E-mail: tarnay.laszlo@pte.hu
}

\begin{abstract}
The paper investigates two possible critical arguments following the pictorial turn. The first is formulated within ocularcentrism, the dominance of sight, and starts with the right to visibility as a general principle that governs today's digital culture but gets twisted in special cases like the Auschwitz photos of the Shoa, the Abu Ghraib prison videos, or recently the website called Yolocaust. The second is conceived outside the visual culture and is meant to vindicate the other senses vis-à-vis the eyes. However, the argument is truncated here only to highlight the boomerang effect of the other senses: haptic vision. It is the case of visual perception when (a) there is a lack of things to see and (b) indeterminate synaesthesia: when vision intensifies the other senses in the embodied viewer. The two arguments converge upon a dialectic of the visible and the imaginable, which is formulated here as two paradoxes that the discussed examples transcend. By enforcing visibility at all costs where there is hardly anything recognizable to see, they lead to two diverging results. On the one hand, the meaning of "image" is extended toward the unimaginable, the traumatic experience, on the other hand, it is extended toward the invisible, the encounter with the radical Other.
\end{abstract}

Keywords: (un)imaginable, (in)visible, haptic, simulation, synaesthesia.

\section{Introduction}

Visual culture as an independent discipline has grown out of various interdisciplinary approaches in the history of arts, literary criticism, aesthetics, media studies, medical and physical image processing, etc. Its birth can be described as a paradigmatic shift in social sciences, especially anthropology and the humanities, but it also brought a new methodology in natural sciences to render physical processes of non-visual nature visible. In the often quoted Heideggerian parlance, it is the view of "the world conceived and grasped as a picture” (Heidegger 1977, 130). It is customary to refer to its emergence as 
the pictorial turn, which both parallels and contrasts with the linguistic turn that characterized human sciences under the reign of structuralism, but in many respects also influenced poststructuralism. For the sake of convenience, the emergence of visual studies is marked by two events: the appearance of W. T. Mitchell's book, Picture Theory and the introduction of visual studies in the university curriculum in 1994. The main thesis of visual culture is often summarized as the reification of the representational theory of mind: sensations induced by the environment are cognitively processed in terms of available cultural categories. It is the core idea of social constructivism that in order to make sense of the world we need previously acquired categories that at best mediate between us and the world.

To put it bluntly, visual culture entails that there is no sensory perception per se when we simply "stop, look and listen" as well as touch, smell and taste. ${ }^{1}$ It also implies, quite radically, that the (visual) perception of the world is eo ipso the perception of images so that sensory perception is reduced to image processing: there is no essential difference between perceiving the world and perceiving images. However, images "can speak and tell as much as they can show and represent:" they also harbour a discursive power "exceeding those purely iconic or visually discernible" that can be correlated with propositional content (Purgar 2014, 2). It is easy to see that the thesis in question is but a reformulation of the main tenet of the linguistic turn: there is no other -i.e. direct - way to access the world beside language. Knowledge is coded, i.e. represented, linguistically. We cannot get around language and the categorical structure it conveys and rely on the direct perception of images. The analogy between the linguistic and pictorial turn is palpable: instead of the language module it is the categorical image processing that is assigned the main task of understanding the world around us. If Roland Barthes once thought that everything from fashion to pots and pans are structured like language (more precisely, they carry meaning that can be linguistically articulated), Jacques Rancière speaks of "a machine that transforms images and life into coded language” (Rancière 2009, 127, cited by Purgar 2014). Moreover, the meaning of images, especially moving images, is reducible to linguistic, i.e. narrative or argumentative, categories.

1 Ingold (2011, 314), for example, criticizes not only the constructivists of visual culture but of the other senses in that they create virtual worlds, soundscapes and "scapes" of every possible kind, on which interpretation is to operate. The relevance of his observation can be seen in the growing number of dimensions in the names of movie theatres, which do not stop at $4 \mathrm{D}$ or 5D, but run up to even 7D meaning that senses other than vision like touch, thermal sense or the vestibular can be equally simulated. 
20 years after the introduction of visual culture the model is cracking at the seams. It is questioned both internally in its constructivist core and externally in its supremacy over its sensory rivals, the other senses. The aim of the present paper is to sketch a possible line of thought, which pulls together the available threads of criticism levelled at the representational theory of the image or image processing in terms of cultural categories. Two major sources can be perceived that are respectively internal and external to visual culture. The first is the reduction ad absurdum of visibility, a criticism conceived in the heart of visual studies; it is a reduction not only of the visible but, as we will see, of the imaginable. The reconstructed argument ends with what Didi-Huberman (2015) calls "noir," the blackness of imagination, or the unimaginable. Surely, he fancies that there is something beyond that blackness as a way out of the dead-end of the unimaginable. But is it a real alternative? A midway between the black of no image and the blinding white of nothing but images?

The second source is constituted by the other senses, especially touch or haptic visuality, making up the entire gamut of sensory perception of sounds, smells, taste and touch. In fact, haptic vision begins, where the blackness of the unimaginable has left us: the blurred, vague, undecipherable, de-figured images of Auschwitz, but not only them: the textured images of experimental and other films, the domain of haptic vision also belongs here. Haptic vision offers an entirely different way out of the blackness of imagination. It is not that we reconfigure, re-identify or even term, personalize the incinerated nameless bodies of the dead, and bring them to light, develop the under- or overexposed image as when the outlines of the Face emerges clearly on the photo paper like the face of Jesus on the Turin's shroud. The difference between the face as portrait and Face as pure exteriority can be given an ethical interpretation. Jean-Luc Nancy (2000) trades the gaze (regard) for the face as the genuine subject of a portrait and thereby avoids the whole problem of reconfiguration. At the same time, he also bypasses the formal-material aspects of the image and thereby of the present framework. However, it is a very interesting line of argumentation that is worth pursuing in a further work.

\subsection{The Weight of Ontology}

Let us start with the first source of criticism that emerges from within the order of the visible. The supremacy of vision in general is deeply embedded in the history of Western thought. Aristotle considered sight as the most noble of the 
senses for three reasons. First, vision is the sense organ most detached from the object of perception. It is - unlike the other senses, especially touch and taste almost completely unaffected by subjective bodily experience. Thus, it is the most objective sense. Secondly, it offers the most reliable, the most specific and the widest range of information about the world. And thirdly, vision - again unlike the other senses - is the least transitory or evanescent source of information. ${ }^{2}$ Sight is comprehensive: it embraces the objects in the visual field in a permanent grasp.

That our age is going digital has two far reaching consequences. Although they are conceptually related, let me consider them separately. The first maintains and corroborates the supremacy of vision. The switch from analogue to digital was precipitated in the first place by the simulation of visual perception. Digital technology produced various techniques and technical gadgets from 360-degree cameras and interactive or motion sensitive virtual helmets to quasi immaterial screening surfaces, which altogether present to the human visual system a sight almost, if not totally, indistinguishable from normal human visual perception. Such a "perfection" of visual simulation can easily be misrecognized for a new ontology. Misrecognized, because the new objects of virtual reality depend both on the image generating digital system and the image processing modules in the human brain. ${ }^{3}$ Ontologically, they are at best the "objective correlatives" 4 of the coupled processes in the human-digital machine complex.

It is possible to argue that visual simulation transcends the normal conditions of perception because it displays a couple of visual and optical features that are alien to human sight (multiple and changing viewpoint, zooming, deep focus, nonhuman and unnatural camera angles and positions, etc.). The said features modify the subject-object relation of normal perception. The viewer sees the diegetic world of the film differently than scenes in real life. That films have -

2 The terms ocularcentrism and heliocentrism are used in literature to refer to the deeply visual character of the philosophical and intellectual history of the past 2,000 years. For further information, see Jay (1993).

3 It is important to see that the human visual system is constituted by several modules. From the lowest sensory bottom level to the higher conceptual ones.

4 The term was used by the English poet, T. S. Eliot in his essays on the metaphysical status of fictional metaphors in $16^{\text {th }}$ and $20^{\text {th }}$ century poetry. I believe there is a clear analogy between how the metaphor depicting or visualizing two lovers conjoined and intertwined can be depicted or visualized as the legs of a compass (in the often-quoted metaphor of the English metaphysical poet, John Donne) - they are the lovers' objective correlative - and the avatar of a player or any other virtual object being there to be manipulated by him. Digital simulation is a much better or more deceiving method to canvass a "Platonic" realm than verbal icons or even the painter's brush were, because it simulates visual perception instead of representing mental objects. Although the analogy offers an interesting historical explanation of the use of digital simulation, nothing in my argument presented here depends on its soundness. 
even radically - changed the way we see is a widely held belief. Such a view, however, cannot explain the equally shared idea that digitally generated moving images engulf the viewer despite the fact that they are located outside of the virtual world. The phenomenological idea of embodiment is meant to do the work here. "What we see in the film has, indeed, some kinship with our normal embodied perception, but it is enhanced and transformed through correlation with privileged viewing and hearing positions that are not available in our 'normal' perceptual mode. The aesthetic space of film is one of hyperbodiment - a belonging to the world that is based on embodiment but which exceeds its restricted viewpoint." (Crowther 2016 - the use of italics belongs to me.)

However, even Crowther's idea of hyperbodiment fails to account for the fact that such embodiment becomes "naturalized," while "we do not confuse watching a film with perceiving real immediately given actions and events." (Crowther 2016) That visual simulation is thoroughly immersive cannot be explained away with sheer habit. If watching digital moving images submerges the viewer into its virtual world, it means not only that they are embodied in it having "a simultaneous in-and-outof-body experience - a hyperbodiment," but also that their sensory experiences however distanced or removed their existential body is from the virtual world - are infinitely similar in kind to normal perception. It would be indeed quite shocking - and not the least incredible - to learn that our visual system became different as a result of film viewing. What is different, however, is how the snapshots are processed or 'interpreted' by our visual module. Digital imagery appears to be a prosthetic device in an analogous fashion to, say, the microscope: it makes things visible, which would otherwise remain imperceptible. The bird's eye view or multiple views of a scene, the slowing down of a recorded event or an 'impossible' angle shot constitute a challenge to human vision not because we are hyperbodied (freed from the constraints of our body), but because we are untrained to construct the sequences seamlessly. Yet they work because we can project our viewing position to almost any other position through the camera, provided there are visual clues that can be processed by some submodule. An aerial photo may have remained forever indistinct to a primeval man, but it can equally be that he would have been able to project himself to a bird's position on the basis of some lookout experience. I call images or image making devices that require such visual projection prosthetic devices. And just as we should learn how to look into a microscope or telescope (i.e. learn what to see) we have to be visually trained to process filmic sequences. ${ }^{5}$

5 It is a tenet of ecological film theory that we perceive and process filmic images with the same visual system that we have developed throughout our evolutionary history. To use it for 
As for the ontological consequence of our age going digital we have to consider the cognitive aspects of the supremacy of vision. The simulation of visual perception is then processed by our visual system seamlessly, so much so that it comes very close to normal perception. As a result, "in watching a film our orientation is one that wishes for information or entertainment, i.e., is content-determined." Hyperbodiedness leads to a "simply ontological" reading of digital images. Such an interpretation explains why immersiveness overcomes the critical awareness of film viewing. It is further corroborated by the fact that simulation of perception is accompanied by an increasing degree of interactivity, which adds considerably to the effect of reality of digital images. ${ }^{6}$ By acting (and reacting) we create the sense of space in our own body. ${ }^{7}$ Or to put it simply, the more we act upon reality, the more we believe in the existence of that reality.

Interaction or manipulation does not sit well with the ambiguity, uncertainty or flexibility of meaning. Action-oriented perception calls for immediate action. Simulation of perception is probably the best interface between the image generating machine and the human perceptual system. However, it is not without

other but similar purposes, we have only to learn to compute bird's eye view on the basis of known clues like the vertical movement of rain and the horizontal surface of the earth. Once it is computed, hyperbodiedness comes spontaneously. To see the relevance of training the eyes consider another sensory module, hearing, the second in the classical hierarchy. It is far more difficult to project our hearing body to another position on the basis of known clues. For example, we project the speaker on the telephone to the other end of the line, if their voice is weaker and scratchy on the basis of using the phone in real life. But if the direction of the sound source is not marked, it would be immensely difficult to locate the source on the basis of its intensity or tone. The Dolby stereo system was once developed precisely in order to simulate the source of sound relative to the existential body of the viewer and to increase the intensity of the effect of horror movies: the cracking of branches is heard from behind the viewer in the auditorium, and not simply from behind the character. Note that in that particular case hyperbodiedness is in fact pure embodiedness without anything like "a simultaneous in-andout-of-body experience," since we hear exactly what and where the character hears. (For further detail, see Branigan 1997.) But probably the best example for the lack of aural projection is hearing our own voice from a recording. We all have experienced once in our life the shocking revelation that our recorded voice sounds very differently from how we hear ourselves speak. It would be equally impossible to simulate the source of an odour in a film on the basis of known clues as it is impossible to simulate the tactile perception of a character on the basis of other tactile clues. Note, however, that another type of perception, the visual perception of an object, say the bark of a tree, can be such a clue.

6 Mark B. Hansen argues that new media "putting the body to work (even in quite minimal ways) has the effect of conferring reality on an experience, of catalysing the creation of a singular affective experience, that is, one that is qualitatively different from (but that can be deployed to supplement) the 'verisimilitude' or 'illusion' of the cinematic image." In other words, interactivity, just like touch, by making the body work, creates an ergodic dimension to the experience of visual images. (See Hansen 2004, 38.)

7 It is called the ergodic dimension of human perception. For further information see Hansen (2004). 
irony that the pre-digital forms of the image, i.e. photography and classical cinema, although hardly non-action-oriented, were repeatedly declared to be inherently indexical and ontological. Reality weighed down heavily on the technical image. No wonder that one of the most adamant critics of the ontological weight of images, Didi-Huberman says that the question of the ontology of the image is entirely misplaced today, meaning that images have never been fixed entities with fixed meanings: they operate this or that way, they affect us, they are used for diverse and constantly changing purposes, but at the same time they also recall, reiterate, bring back or turn back to other times, repressed or forgotten memories. (See Didi-Huberman 2008, 15.) It is the pragmatic or action-oriented aspect of visual images that determines their ontological import. Whether they were produced in a causally effective instrumental way so dear to Bazin or Kracauer or they are generated by a computer program is secondary to how they are contextualized through action.

\subsection{Visibility as Monstration}

With the arrival of the digital simulation of perception, the question of the ontological weight of images returns in full guise. The Platonic realm of images comes to have the upper hand as a result of two distinct aspects, which work in tandem to cement the ontological meaning of digital images. The first is prima facie a pragmatic aspect of their divulgation, but it turns out to shape their semantic power as well. Dayan (2013) calls this key social factor visibility, or more precisely, the right to visibility. To make visible has become the unwritten prerogative of social networking, but it is grounded on a general condition of possibility of any photographic (and possibly all other) images: "behind any image, one must imagine a body that gestures, calling for your attention" (Dayan 2013, 146 referring to Belting 2004). That is, every image is intentional: it is there only to be seen. It entails that it is shareable. Shareability on the internet has far reaching consequences, which I will briefly discuss below. But there is another important aspect of digital images that weighs heavily on their ontological interpretation. It is inherent in the cognitive understanding of digital images. Even if we accept that images can mean this or that thing - be it real or virtual -, as a result of the human-digital machine the life-like simulation of perception obscures the meaning generation process and creates the effect that what we perceive on the screen - be it real or virtual - is real. Let us take the two aspects of digital culture one by one. 
Dayan interprets the general power of shareability of images in the field of communication as a force akin to illocution in language use. When an image is "shown" ("monstration" is the term that he uses), it displays the force of an affirmative utterance, which states a fact. Posting an image is a performative act with different forces. There is an essential difference, however, between language and visibility. While an utterance is grounded on a given propositional content that is also expressed with the act, the informative content of a monstrative act has an ambiguous status. Sometimes information is only apparent, that is it is completely covered up by monstration; some other times they are stated in it: "All media monstrations create faits accomplis," but sometimes what is shown does not merit the title of information (Dayan 2013, 148).

The problem lies, I think, in the difference between information and fact. While the difference between propositional content (information) and reference (fact) is semantic well-known to the philosopher of language, a posted or shared image may be grounded on information, which cannot be judged to be true or false. In other words, when monstration substitutes or "covers up" information, it blurs the distinction between visible content and its corresponding reality. ${ }^{8}$ The visual ontology of the image is doomed to be ambiguous between the so-called "real" and the virtual. But at this point, paradoxically, the analogy with language either breaks down or can be carried further. The illocutionary force with which an utterance can be used is always a function of the given propositional content. The factual content (information and fact blended) of an image, on the contrary, is a function of the monstrative act. To paraphrase Dayan (2013), the force of a monstrative act can be so strong that it either overshadows all informational content (if there was anything real before the monstration), or on the contrary, it generates its own virtual content.

But one might want to restore the analogy by pointing out that (i) an illocution is never graded (stronger or weaker): it is either acted out or not, and that (ii) there

8 The analogy is between Bertrand Russell's famous example, "The present king of France is bald," and an image of a situation. While Russell's utterance presupposes that there is a king of France (which is not the case), the image also seems to presuppose that what it shows is real. However, we know that neither presupposition should be necessarily true in order for the utterance or the image to make sense. But while we can say as Russell and other analytic philosophers held that the original utterance can be variously at fault (being false, empty, senseless, or infelicitous just like an Austinian speech act can be), an image made visible constitutes a "fait accompli" for the viewers discrediting or rendering futile any effort to assess or verify the corresponding truth claim. Where fact and information merge everything that is shown becomes eo ipso true, while what is not shown, does not exist. Thus, by showing the image of the present king of France we would not simply presuppose but downright state that there is a king of France, the one shown in the image. 
exists a special category of declarative speech acts when the fit between language and world in Austin's words are created with the utterance. In such cases the use of language does not describe the world (e.g. the Earth is round) or commits to changing it (e.g. promising something to be done), but makes its referent be (e.g. giving a name to something or someone). Such is also the divine order of "Let there be light and there was light," where the first declarative is neatly separated from the second affirmative. Such a neat distinction, however, cannot be made with some corresponding image of creation. Think of Michelangelo's famous fresco in the Sistine Chapel, where we see the figures of Adam and God and their hands extended toward each other without touching. Like the lovers of the urn in John Keats's poem Ode on a Grecian Urn, who "winning near the goal” can never kiss, but remain forever suspended in air. But they have a neat compensation: "For ever wilt thou love, and she be fair;" it means that time for them comes to a standstill. I think it is very instructive to note that the suspended scenes on the vase for Keats are nothing but a pretext for what he calls negative capability, meaning that one settles for half-knowledge or is able to remain in half-truth. Thus, we are left with the half-knowledge that the gap between Adam's and God's hands stands for the act of creation, God declaring that Man exists, or it shows the result of the creation affirming that man exists. It is the half-truth Dayan refers to, by quoting Judith Butler, that every photograph is already an interpretation. To put it more precisely, it is because what an image shows is half-truth that it demands interpretation. Furthermore, the image itself appears to be an interpretation because its factual content cannot be directly unfolded. While the informational content of God's will can be juxtaposed to the referential description of the existing light (and of all the rest of earthly things) in a verbal text, information and reference are inextricably overlaid in an image.

\subsection{The Simulation of Perception and the Virtual}

The second cognitive aspect of digital image processing was probably a motivating force to make images as early as ancient or probably prehistoric times. The urge to duplicate, reproduce or make a copy of the world may have been one of the main motifs to draw, paint, photograph and last but not least, simulate visual perception. The reasons are various and extensively debated: they range from the will to act upon reality to ritualized magic. Today we would say that Man has always wanted to extend reality in some other realm only to get back to the real. Mixed reality as a form of virtual reality is a case in point. The road from the legendary lifelike paintings 
by Zeuxis and Parrhasius through the discoveries of optical illusions and films to contemporary video graphics was long, but the underlying idea is unmistakable: to produce a perceptual input to our visual system that processes on a par with normal visual stimuli. Note that the term "indistinguishable" is not the proper term to use here to compare the normal and the simulated stimulus. For the human visual system as any other neuronal area is robust enough to compute a full-fledged picture of the world even on the basis of a poverty of stimulus. Were it not such a black-and-white and badly lit footage, it would never be seen as a documentary of real events. ${ }^{9}$ It means that $a$ fortiori an (almost) full-fledged simulation of audiovisual perception grabs the viewer's mind with an even stronger sense of reality.

In general, the ontological weight of images seems to be an unavoidable corollary of digital visibility for two reasons. Firstly, because the image reverses the functionality of information (propositional content) and monstration (illocutionary force). Secondly, because the simulation of perception feeds an input to the visual system, which is prima facie indistinguishable from what normal perception provides.

The weight of ontology is however further extended to other senses by new media with the use of virtual helmets, telepresence, mixed reality, etc. Since it is still futuristic to simulate other sensory perceptions than the visual and the aural (though certain attempts have been made for example to simulate the olfactory), new media combines the virtually perfect audio-visual input with somatosensory and kinaesthetic effects. The combined net effect can be defined as an (in)determinate form of synaesthesia when the other sensory effects of the perception of an object are activated by and through the spatially stereoscopic audio-visual perception of the virtual. ${ }^{10}$ Since it happens many times in everyday experience that we do not have a full-fledged perception of an object or event - Merleau-Ponty's $(2002,267)$ example of the twig bouncing back after the bird has flipped away is a neat case when we seldom hear and feel the bouncing of the twig, yet through synaesthesia vision complements the missing sensations

9 Certainly, other conditions like realism of style should also apply, which I cannot summerize here.

10 I proposed in another paper that synaesthetic effects should be represented along a continous scale from perfect or determinate synaesthesia, when many or all the senses come together and converge on a definite object providing a full-fledged experience to indeterminate synaesthesia, when the given sense stimulus, most often the audio-visual, is reduced or poor to lead to the identification of the potential object. In the latter case the other senses may become all the more acute to compensate for the poverty of the visual. However different the motives for synaesthesia are in the two cases (complementary vis-à-vis compensational), the synaesthetic effect is often rather gradual than exclusive. (See Tarnay 2015.) 
- virtual or extended reality technology capitalizes on the very same robust capacity that works in less than optimal perceptual conditions. Whether the ontological weight of perceiving a dim, blurred figure is a result of an inference in the perceptual system about the content of perception or it follows from the direct pickup of information by organisms in general constitutes the core of the debate between cognitive and ecological psychology. It does not influence the argument proposed here, however. For if perception is embodied - that is, it works in unity with the subject's bodily movement, i.e. their actions - the weight of ontology imposes on the entire perceptual system more heavily. New digital technology complements André Bazin's and Siegfried Kracauer's instrumentalism about the causal power of the camera by revealing that the perceptual system is disposed to take real what it perceives, provided it works between the hard-to-define bounds of robustness or in less-than-optimal perceptual conditions.

Thus, the original indexical power of the photographic image that conveys information (truth) about a part of reality is paradoxically preserved in the digital age. To put it roughly, only what can be posted, i.e. shared on the internet, is (taken to be) real. But the power is twisted: it is not that the image is ontologically real because it needed reality to be produced in the first place, but the other way around: it is because the image exists that we have access to what is real: the Other of the image. The difference between the visible and the visual collapses or is about to collapse. As a result, the imaginable dissolves into the visible.

However, there are two distinctive parts of visual ontology that digital culture supports: a real and a virtual. The first is sharable "reality," the second is the effect of the simulation of visual perception. Consequently, everything including the imaginable becomes an image as if all other senses were subservient to it as part of a haptic or synesthetic effect. Put together the real and the virtual ontology of the digital image exerts a devastating effect on the Heideggerian conception of the world as an image; not because it destroys it, but because it ingrains it. It is no longer a question of representing reality for two reasons. First, because images demand to be acted upon - they are interactive - and as such, they substitute or create reality. It is a corollary of the ergodic dimension of perception. Second, because external, physical images are seen as incarnations of internal, mental images. The imaginable and the shown become one. The idea that what cannot be imagined cannot or should not be shown, like the Shoah, and the idea that virtual reality like simulation is or should be perceived as reality, two faces of the same coin: images are all that there is. The social and cognitive conditions of monstration exclude both the unimaginable and the invisible. 


\subsection{The Weight of Ontology Revisited: The Power of the False}

We can hardly foresee even in rough outlines where the technology of virtual reality would lead us and how it would shape the ontological weight of (moving) images, if the simulation of visual perception can still be called images at all without a proper vehicle like canvas or screen needed to carry the image. "Materiality would anyway be inappropriate as a term for today's media. A media is form, or it transmits the very form in which we perceive images," writes Hans Belting $(2005,305)$. However, the materiality of digital images is ungraspable or at least elusive. In lack of anything perceptible or physical to carry or transmit the image, the ontology of the virtual is created - through the simulation of perception - by the perceiving agent. Furthermore, if the analytic distinction between image and material vehicle does not apply to digital images, it is difficult, if not impossible, to differentiate the image from the specific form it is transmitted in. Form, if identifiable at all, is the form of perception, not of the image: perception is subjective embodiment and as such is confined to the limited position of the viewer, even if the actual viewer can shift their position almost limitlessly with every (new) virtual perceiver. The perceptual paradox of new media runs counter to McLuhan's famous dictum "the medium is the message," where the form of the medium was determining: now the perception of the virtual is the message. New media postulates a subjectively embodied viewer-agent in the virtual world, who coincides or correlates with a fully-fledged viewer embodied in the real world. ${ }^{11}$

Although it is not entirely clear how we should understand it, it seems form encodes everything that is due to the way how the image is produced: both the machine's and the image maker's contribution from camera angle, position, framing etc. - everything that Didi-Huberman calls the use value of the photograph, the formal and stylistic play that opens it up to manipulation and interpretation, and consequently, renders it inadequate to the object it is an image of. The result is that the image "lies," that is, it tells a half-truth. New media, especially the

11 A qualification should be made here. McLuhan considered each medium to be an extension of man's senses, which are called prosthesis today. While he says that electronic media makes the medium to be the message, he refers to the method of cubism of reducing the three-dimensional representation to a single plane. Thus, he avowedly sees medium-consciousness as part of what Richard Wollheim (1968) calls the seeing-in, i.e. the form of seeing adequately to pictorial representation. The simulation of perception that current new media brings to perfection tends to erase that consciousness in favour of the "ontological weight" of virtual reality. It would be difficult to deny that simulation is a further extension of our senses to the point that the gadget becomes in every way prosthetic, but it would be equally hard to maintain McLuhan's original commitment that it is indeed the medium that is the message á la Picasso or Braque. 
simulation of the virtual not only bypasses the materiality of the "old" image, but it fuses its form with the laws of (normal) perception. The use value of digital images lies not so much in their potential to relate to the changeable world, the cultural context, or to be re-contextualized in the terms of one's personal history; digital images are used to enact and re-enact real and virtual situations, in which the ontological weight of the images swings back with full force: what we perceive is - by the nature of (simulated) perception - real.

As I said earlier, I cannot follow the history of the new ontology of the image here, simply because it would require a futurologist. What should be considered instead is the critique of the inadequacy of the image as half-truth, or using another popular term in French philosophy, the power of the false. Such a critique should go back to the distinction between the physical image reproducible in whatever medium, as Walter Benjamin meant it, and the mental image that has been common currency in psychology. Didi-Huberman relates the idea of the false image, the image that lies, to Lacan's half-saying. The obvious reason is that the imaginary, which corresponds to the mental as imaginable (including the unconscious) is never exhausted by the visible. There is always more to the imagination than meets the eye.

Between the two extreme positions, Barthes's punctum, the "this was" or the full indexicality of the photograph and the simulation of embodied perception, there is the indefinite terrain of the formal or stylistic play of the image being inadequate to the ontology of the world as it is. It is the field of Lacan's halfsaid truths, the supremacy of the signifier of the lack of the Real in the Other. Since the latter in Lacan is associated with the structure of desire as a lack in being the weight of ontology becomes a lacuna, a hiatus to be filled in, that is a pre-ontology. It is the image as signifier that carves out the territory of the unconscious as the non-imagined or non-imaginable (Lacan 1986). But the image as signifier is a material image, most often reflected in the mirror, that should be distinguished from its meaning in the Other, the mental image. I would contend that the lacunae in the Other correlate with a lack of the imaginable or a kind of "forbidden" or traumatic image. For everything that can be shown is inadequate to that mental image. It is why people like Lanzmann are constantly censoring the representation of traumatic experience. However, not only the traumatic, but anything that is private, personal or intimate is confined to the bounds of interoceptive experience. Whether the traumatic and the interoceptive experience differ in constituting censored and uncensored imagination respectively, I leave to psychoanalysis to decide. Here I would claim only that both can be correlated 
with a lacuna, a lack of existing things to see. Consequently, the only way for the imaginable to regain visibility is by means of images, which do not represent or denote things, but adumbrate them at most.

But before moving on to the critique of the photographic image, let us take stock. It seems the argument about visibility reached a stalemate. On one hand we have the sweeping force of monstration, an iconolatry, where visibility is the prerogative of truth. On the other hand, there is iconophobia, which "has stressed the unimaginable (Lanzmann), unknowable (Lyotard), and ultimately unrepresentable (Lévinas) nature of the Holocaust since the 1980s" (Larsson 2012). Two extreme epistemic positions concerning visibility: an unlimited ability to produce images (Facebook generation) and the unimaginable, and various forms of prohibiting images. The origin of the conflict between the two appears in the Book of Creation, where God creates Man to his own image: "And God said, Let us make man in our image, after our likeness" (Genesis 1:26) and then God forbade Man to make any image: "Ye shall make you no idols nor graven image, neither rear you up a standing image, neither shall ye set up any image of stone in your land, to bow down unto it: for I am the LORD your God.” (Leviticus 26: 1) Image making and the prohibition to make images have the same source. Producing an image is justified, if it is creating ex nihilo for the image itself as the result of a declarative act: what is "shown" exists. Making an image, however, is unjustified, if it is created after an existent that transcends the bounds of imagination.

Surely God is like that. But what else? Death may come second. Traumatic experiences third. And so forth. What we have here is the myth of the unrepresentable that determined culture in different periods and to different degrees. It took for instance hundreds of years from antiquity through the middle ages to romanticism until poetical thought replaced God's creative power with the poet's furor poeticus to create ex nihilo. But if we cannot give face to the "unimaginable," we leave it to eternal forgetting. It was a lesson that the Church learned after the age of iconoclasm and in an age of illiteracy, that without the painted images on the church walls, religious power would deteriorate. And it is also the paradox of the Shoa and the paradox of invisibility that iconophobia leads to forgetting the unimaginable. ${ }^{12}$ In contrast, we have the right to visibility, which can be extended as far as to show the unimaginable. The paradox of visibility reaches out to the unimaginable to unforget it: to create "memory pegs" in the minds.

12 László Nemes Jeles, the author of Son of Saul (2015), talked at a conference about the selfcensoring tendency of the first and even second generations of Holocaust survivors. The selfinflicted censorship of almost any representation of the Shoa included verbal testimony as well, and became a collective strategy of forgetting the unimaginable. 
Perhaps it is the menacing force of both paradoxes that fuels critical arguments, like Wajcman's, against people like Didi-Huberman and the author of Son of Saul (2015), Nemes Jeles, who occupy a middle position between the two extremist positions of visibility or iconolatry and invisibility or iconophobia. What happens, if we lift the ban that God placed on man not to make images? Although there is a scale of so-called middle positions between the two extremes of visibility, lifting the ban we may quickly end up with terrifying examples. Let me briefly discuss three cases here.

The first is the well-documented case of the Abu Ghraib prison photos and videos that American soldiers shot about the tortures they themselves inflicted on Arab prisoners. The images are horrendous not only because of sufferings they show the prisoners were exposed to, but because of the attitude of the American special army unit headed by a woman, a Gulf War veteran. The guards, especially the woman, obviously enjoy the abusive acts committed against the Arabs; for example, there is a photograph in which she shows the victory sign while leaning over the dead body of one of them. The acclaimed film maker, Errol Morris, made a documentary of the found footage intercut with personal interviews, in which the soldiers recount the events separately. Morris was highly criticized for not judging the perpetrators openly while letting them speak for themselves. What is really shocking, however, is how the US soldiers view their own deeds. When the director asks the crucial question: "Why did you photograph the actions?", the answer is: "We did it for our own pleasure." That is, not to circulate the photos publicly. ${ }^{13}$ It has a double edge. On one hand it attests to the iconolatry of the soldiers, on the other hand, it tests the conditions of iconophobia on the part of the public. Confronted with the photos, do we feel ashamed because of the inevitable identification as viewers with the abusers? Or do we feel horrified at the violence displayed? Or probably both? The images, it seems, violate both taboos of what is showable or representable and what is imaginable. To put it differently, they short-circuit the two paradoxes of the visible and the imaginable as two horns of the same dilemma: what is shown (or is shareable) is imagined and what can be imagined becomes a visible image. There is nothing unimaginable, nor is there anything unshowable or invisible.

13 Here I disregard the obvious fact that with this answer they meant to disclaim the responsibility for recording and divulging the horrendous deeds as potential propaganda. Private, or even perversely intimate, pleasure vis-à-vis public entertainment. Since I am not concerned here with moral justice, but with visibility as a form of unforgetting, I would only emphasize the contrast between the silence of the survivors of the Shoa and the obsessed photographing of the Abu Ghraib torturers. 
If we want to resist the destruction of the unimaginable and invisible, we should turn to Georges Bataille. He possessed a photo of a Chinese man undergoing an excruciating death by cuts. It is contained in his final book, The Tears of Eros. The ritual of executing by cutting the body and incurring the slowest death possible was still practiced and photographed in China around the turn of the twentieth century. Bataille was obsessed with the image, which he found both "ecstatic" and "intolerable" for it "tears at the limits of the image and [...] it reaches us through its violence and in its violence, it demands a response from us" (Noys 2013, 25). However, what Bataille sees as ecstasy on the face of the victim at the gate of death is rather an amalgam of a grin and a grimace, the effect of the opium given to the victim to prolong or relieve his pain. To translate it into the terminology used in this paper, the grin remains to be invisible under the grimace, and as such, it is also unimaginable, at least without interpretation. In the context of the Chinese Man, the grin on the face of the female boss of Abu Ghraib calls once again for our interpretation: the collapse of the visible and the imaginable is at the expense of interpreting her gesture of victory as an unimaginable Satanism, as Bataille may have seen it. In contrast, the photos could have equally functioned as multiple triggers of narcissistic desires akin to the "opium-effect" of pornographic pictures. They have nothing to do with the events they show (ontological weight), but with how they (as visual aids) send their viewers into a vortex of sensual joy. The unimaginable, "the ecstasy of death" once again slips into the invisible.

My third example is closer to the right to visibility, that is, iconolatry than iconophobia. It is not long ago that Yolocaust appeared on the World Wide Web. Its name contains an allusion to the Holocaust. It was an individual reaction to a trendy phenomenon that young people make "funny" selfies astride on memorial sites of the concentration camps, including the Berlin Holocaust Memorial. The temptation is inescapable to interpret the selfies as mocking the victims of the camps. An artist, Shak Shapira was so shocked at the mockery that he set up a site, Yolocaust where he posted photographs combing the frolicking figures in the selfies with hecatombs of the concentration camps. Shapira brings the right to visibility ad absurdum precisely in the sense that Daniel Dayan defines it: it is not only the right to display oneself in whatever situation, but the right of conferring visibility on others in whatever context. It is the latter clause that renders the right absurd for it surpasses the bounds of the real. The question is no longer the ontological weight of the image, but whether it is still imaginable. However, remember the dictum that only what can be posted and shared is real: Is there anything imaginable beyond 
that Real? Shapira's strategy is telling. He would take the incriminating photo of anyone off the site, if the person expresses her regret to have grinned at the holocaust victims. Thus, he (Shapira) proves that reality is visually constructed and/or deconstructed..$^{14}$ The imaginable is only subservient to that virtual reality: the imaginary and the Real once again merge. In other words, the virtual has no alternative, not even the unimaginable. For as soon as we would think of anything beyond visibility, it becomes imageable. We have seen that imaging as monstration is like a declarative speech act: it confers existence on what it shows. Now we see the opposite: erasing from visibility deprives the scene of existence.

The same process of coming into and going out of existence through visibility in our culture from sex and post-orgasmic selfies to crying ones: becoming an image confers existence, but it can also drive someone out of existence. Sites like the Blue Whale most recently incite to post images of self-inflicted wounds more and more serious until the person is ready to commit suicide online. Visibility is now I contend in the state of a "logical" apocalypse: ${ }^{15}$ anything is visible because anything is imaginable, and vice versa. In the context of the apocalypse of visibility, anything can be shown and can be revoked. No wonder that the Holocaust images have caused so much trouble, for they either provoke iconophobia or invite hypertrophy to amend them, "to see everything in them," which means iconolatry, "icons of horror" (Didi-Huberman 2008, 34). The argument is clear: images like photographs should be directly - that is, without interpretative tools - recognizable. And rightly so. The trend in digital technology has almost exclusively been to improve the visibility - that is, the graphics of the images. What a picture shows should be anything but vague, blurred or undiscernible, and last but not least, it should not indicate or attest in any way to the context of its making. It is why the first doctoring of the Auschwitz photos was to crop the black framing that indicated how the photos were "snatched from reality." If they became indeed "icons of horror" purged of everything invisible in the original copies, it is all the more surprising why Didi-Huberman says of the latter that they - not the retouched versions - both "address the unimaginable, and refute it" $(2008,19)$.

14 The French satirical weekly magazine, Charlie Hebdo follows a similar policy when mocking the main tenets of Islamic belief. The line is that nothing is taboo: anything can be shown in any context. Whether we laugh at a Hebdo comic or feel shocked by a Yolocaust image of grinning youngsters depends purely on the ethical or ideological frame of mind of the viewer: the images themselves are not ethically or ideologically laden.

15 By "logical" apocalypse I mean apocalypse à la logic: a situation in logic when from a (true) proposition anything follows, even its opposite. 
The reason, I think, lies in the attempt to evade the apocalypse of the visible. While he may be right in claiming a middle ground between pure indexicality and the right to visibility, the thought, that (only) the four photos that are "snatched from reality" can address the unimaginable, is highly debatable. The explanation he comes up with is the idea of the image as montage that he borrows from Eisenstein. For Didi-Huberman to show is to put what is shown into relation, to (re-)contextualize it. In other words, the visible is never recognizable per se: it always relates to the (un)imaginable in the mind of its viewers. What makes the Auschwitz photos so special is that they establish a relation between the hardly visible or blurred and the unimaginable, the traumatic that is so horrific that it is forgotten and the image brings it into memory. It is the "mémoire involuntaire," the mental image thus excavated from the layers of the unimaginable that is horrific, not the real image, the photo. Yes, it is the real event of the holocaust that is horrendous.

The question that we should ask is this: why is it that only the undoctored, blurred images can relate us to the unremembered event? Why cannot a graphically impeccable image uncover hidden memories of the past? However, it is not precisely what I would like to address in the last part of the present paper, for it has a negative presupposition that high visibility cannot evoke unwanted memories. Although I am sceptical whether it can, I do not have any perspicuous argument to prove it cannot. Instead, I would like to argue that images, where - to different degrees - there is a lack of recognizable things to see, can relate us to the unthought or non-thinkable, whatever it may mean. Not because the blurred image and the unthought are analogical in that they are both unformed in some way. The cognitive route from the image of the unrecognizable to the unimaginable is far more complex.

\section{The Unimaginable as Visible Content: Pure Sensation}

First, it should be noted that the prohibition to show versus monstration bears an analogy with Foucault's definition of discourse. Iconophobia defines and redefines not only the imaginable, but also the thinkable. There is an even stronger analogy with Lyotard's figures of discourse that testify and govern the pertinence of concepts, of what is thinkable. "A figure is defined as a visual or textual element that permanently transforms some way of thinking, reformulates a concept, changes or decides the meaning of a descriptive category." (Leśniak 2013, 187.) The term "figure" is used in an entirely different way to the 
figurative understanding of images that any kind of "doctoring" is aimed at. On the contrary, figure here refers to an element that works against the polished, graphically impeccable image by unsettling or unfolding the basic concepts of thought. The operation is amply discussed in French philosophy from Foucault, Lyotard to Deleuze, Lévinas even if under very different names with divergent senses. Didi-Huberman borrows the idea of montage from Eisenstein only to state that the images, while reveal one thing, cover up another thing: in part they represent truth, in another part they are fiction. They are like folds: they should be unfolded. ${ }^{16}$ But what matters here is not so much the creative potential of images as figures; it is the idea that what sets the disruptive process of thought in motion is always the physical or sensible material, like the black frames of the Auschwitz photos, which were first cropped. It is the "material practices and formal qualities of representation [that] influence the operation of the basic concepts of thought defining the thinking on the Holocaust" (Leśniak 2013, 188). But what should we understand by "sensible materiality" that disfigures (in) the image? Didi-Huberman speaks about the lacunary nature of images: "there is an incapacity of the image to transmit all of the real." The image is an image despite the fact that "not all the real is solvable in the visible" and "there is an incapacity of the image to transmit all of the real" $(2008,59)$.

It is a thesis about the extension of the word "image," while the intension is unmodified: it is an indexical relation to the real, to what is happening. He wants to overcome the unimaginable by looking at the photos where there is a lack of things to see. But he would never go so far as to say that the sensible materiality of the image mediates between imagination and the eyes. Neither would he agree that unforgetting requires the retraining of the eyes. ${ }^{17}$ Following Leśniak I would argue instead that the formal-material qualities of the image precede any ethical and political understanding, precisely because the understanding of visual figures becomes indeterminate, unstable because of the physicality of the image, which, in turn, evokes desire in the viewer. ${ }^{18}$

16 Cf. "La même image nous montre quelque chose et nous cache quelque chose en même temps. Ici elle révèle et là elle replie. Elle porte une certaine vérité et elle apporte une certaine fiction. Elle a donc elle-même la structure d'un pli." (Didi-Huberman 2011, 16.)

17 Retraining is a term used by Taberham (2013) with reference to experimental film making, especially Stan Brakhage's embryonic vision when figurative understanding is subjected to the formal-textural qualities of the image. The term can be given a wider meaning by applying it to the formal-material qualities of the image vis-à-vis categorical perception.

18 Lésniak follows Rancière in his pursuit of a psychoanalytic critique of aesthetic form as defining what is thinkable. He defines visuality on the basis of visual experience acknowledging that what is imaginable is always already conditioned by material practices, but he never actually asks "how thought is present within sensible materiality" $(2013,187)$. 
At this point I leave the critical line launched from within the paradigm of visuality in order to turn to the second line of criticism mentioned at the beginning of the paper that focuses on the emergence of the other senses. The criticism of visuality grounded on the pertinence of the other senses can be used in favour of a visuality that I have defined indeterminate synaesthesia further above, as one of the poles of a gradual scale of normal and simulated visual perception that ranges from the pure perception of sensory qualities to categorical perception. Determinate synaesthesia occurs possibly, when all the senses come together in the categorical or figurative perception of an object or scene. At the other extreme we find what Laura Marks (2000) and others call haptic vision, when the other senses are not directly activated, but are evoked in absentia of the perceived object. Roughly put, we can formulate the principle that the more blurred the object of vision is, the more haptic the sensation becomes. Consequently, the other sensations become more vivid as well. We may feel prompted to say that full - here indeterminate - synaesthesia mobilizes the other senses in order to compensate for, or even regain, the imaginable: the object that is perceptively "lacking" in the image.$^{19}$ If the image is an image in spite of all, that is because it cannot represent the totality of truth, as Didi-Huberman says, it must be an image minus (parts of) reality. Not necessarily all of reality. Didi-Huberman preserves a residual indexicality of the image, a partial ontology that justifies images like the Auschwitz photos "snatched from the real." He, however, never goes so far as to demand a retraining of the eyes. He does not look for radical sensation. Instead, he aligns with Walter Benjamin, Hans Belting and other aestheticians of the image in that "an image is made to be looked at by others, to snatch from human thought in general, thought from 'outside,' something imaginable that no one until then had even conceived as possible" (Didi-Huberman 2008, 6). While the lacunary nature of the image for him is an instigation to imagine the unimaginable, or to obliterate the obliteration, what is "too monstrous to believe," haptic visuality is a gateway toward the Other's singularity, which cannot be conquered or imagined, but only infinitely approached, intransitively and intimately perceived. For it is not only the traumatic, the horrendous that constitute the unimaginable: what is intimate or intraceptively perceived is equally unimaginable. Yet there is a difference between the unthinkable or unimaginable and the invisible: what is unthinkable is a question of political, ethical law like the inarticulate cries and

19 It can also be argued that there is an evolutionary reason for that compensation: the camouflaged (also called peekaboo) situations, where our ancestors had to identify the predators by some reduced stimuli. Had it been otherwise, most probably we would not be here now. 
silences of the Shoa, the sheer enormity of the crime, an extendable reality of the image of what has happened. What is invisible calls for an intensified perception, an indeterminate synaesthesia of the other senses rather than an extra run of the imagination. The unimaginable correlates with verbal testimony: it is impossible to imagine, there is no proper image, no imagination of the Shoa. But "one must imagine" (Didi-Huberman 2008, 39) in spite of all. Where does this "must" come from? Is it the ethics of the gaze or the image? Didi-Huberman argues, it is the calm but hazy zone of the eye of the hurricane. But maybe it is better to say that it is the blindspot of the eye, or the eye itself invisible to the seer: his or her position on the ground (like the threshold of the gas chamber) and we as viewers must necessarily look into that eye, the Face of the portrait that looks at us.

Haptic vision and moving images, where there is a lack of things to see, constitute another "extendable" reality. The images, instead of instigating to imagine the unimaginable, call for a kind of "pure" perception, where instead of the absolute object Wajcman introduces in criticizing Didi-Huberman, the haptic vision and indeterminate synaesthesia extending the visible toward the invisible, rather than the unimaginable. While the Absolute Object constitutes the universal truth excluding everything that is imaginable, the Face is the singular and irreplaceable Other, the Unthought, which empties our perception of the categorical and challenges all imagination. If it was said earlier of imagination that there is more than meets the eye, now we can say of visual perception that there is more than meets the imagination. Radically speaking, there is no image but beyond the canonical visible/legible opposition.

To finish, let me draw a matrix of four slots representing pairwise the two basic optional interpretations of images, which are in some way "deviant." Such images exemplify what I have called the paradox of visibility (and invisibility). They constitute a binary alternative of visual understanding:

A) snatching from an otherwise visible external reality: here belongs any image that preserves a residual indexicality (an indexical sign of its production), like the Auschwitz photos, which challenge the imagination. Prototypical examples are the animated documentary Silence about the Shoa (Sylvie Bringas and Orly Yadin, 1998) or other animated documentaries, which address

B) traumatic experience as an otherwise unimaginable internal reality like the life in the concentration camps, sexual abuse in family, physical tortures and other horrifying events; 
C) displaying an otherwise invisible reality: here belongs any image, which is grainy, blurred, or hardly legible, which is detached from ontological sources and which addresses

D) as an otherwise unimaginable internal reality, a unique and intimate experience like the transcendental relationship of the old couple in Michael Haneke's Amour (2012) or the intimately carnal relationship of the young couple in Ashley Horner's Brilliantlove (2010).

In (A) iconophobia is a reaction to the visible, which is unbearable, for there is far too much to see. Elem Klimov's Come and See (Idi i smotri, 1985) is a neat example. It also indicates that showing less than the "absolute truth" is either an intentional choice or one enforced by the circumstances. By transcending iconophobia in the other direction (not the "iconolatry" of Come and See), we have the option to show (B) what otherwise would be confined to eternal forgetting. In (C) iconolatry is a reaction to iconophobia, the impossibility to show the unimaginable. It is the power to show what otherwise cannot be shown like the corpus delicti in the enlarged photographs in Michelangelo Antonioni's Blow $U p$ (1966). Transcending iconolatry can lead to (D) the experience of singularity and uniqueness. To show less than the whole truth here is a natural, rather than an intentional choice.

The condition of showing less than the whole truth to the limit of unrecognizability, when there are no things to see, is not mandatory, however. For example, the fluttering butterflies in The Duke of Burgundy (Peter Strickland, 2012) or the naked bodies in the exhibited photos in Brilliantlove are images of lesbian and heterosexual intimacy. They are not metaphors but literal images, which through their extremely sensual nature (the images of the butterflies in Strickland's film are coupled with the strident noise of fluttering wings intensifying the haptic effect) synesthetically induce, or even cause, the experience of singularity in the viewer. In other words, the viewer is affected by the images through embodied perception in her own body. Although I would not exclude in principle a similar highly sensual experience in the case of the Auschwitz images and their likes, I am inclined to correlate the first alternative of visual understanding with the imaginable/unimaginable axis. The second I assign to the sensible-sensual/imperceptible-transcendent. But in sum, together they constitute the axes of the paradox of visibility. 


\section{References}

Bataille, Georges. 2001. The Tears of Eros. San Francisco: City Lights Publishers. Belting, Hans. 2005. Image, Medium, Body: A New Approach to Iconology. Critical Inquiry vol. 31, no. 2: 302-319.

Branigan, Edward. 1997. Sound, Epistemology, Film. In Film Theory and Philosophy, eds. Richard Allen and Murray Smith, 95-125. Oxford: Oxford University Press.

Crowther, Paul. 2016. Hyperbodiment: The Aesthetics of Film. (manuscript) https://www.academia.edu/17485128/Hyperbodiment_-_The_Aesthetics_of_ Film. Last accessed: 15. 05. 2017.

Dayan, Daniel. 2013. Conquering Visibility, Conferring Visibility: Visibility Seekers and Media Performance. International Journal of Communication vol. 7, no. 7: 137-153.

Didi-Huberman, Georges. 2008. Images in Spite of All. Four Photographs from Auschwitz. Chicago: Chicago University Press.

Didi-Huberman, Georges. 2011. La conditions images. Entretien avec Frédéric Lambert et François Niney. In L'expérience des images, [The Experience of the Images], ed. Frédéric Lambert, 6-17. Bry-sur-Marne: INA. http://documents. irevues.inist.fr/bitstream/handle/2042/28239/MediaMorphoses_2008_22_6. pdf? sequence=1. Last accessed: 15. 05. 2017.

Didi-Huberman, Georges. 2015. Sortir du noir. [Leaving the Darkness], Paris: Éditions de Minuit.

Hansen, Mark B. 2004. New Philosophy for New Media. Cambridge, MA: MIT Press.

Heidegger, Martin. 1977. The Age of World-Picture. In The Question Concerning Technology, and Other Essays, 3-15. New York: Harper and Low.

Ingold, Tom. 2011. Worlds of Sense and Sensing the World: A Response to Sarah Pink and David Howes. Social Anthropology vol. 19, no. 3: 313-317.

Jay, Martin. 1993. Downcast Eyes. Berkeley/New York/London: The University of California Press.

Lacan, Jacques. 1986. The Four Fundamental Concepts of Psycho-Analysis. Harmondsworth: Penguin.

Larsson, Chari. 2012. Suspicious Images: Iconophobia and the Ethical Gaze. M/C Journal vol. 15, no. 1. http://journal.media-culture.org.au/index.php/ mcjournal/article/view/393. Last accessed: 15. 05. 2017. 
Leśniak, Andrej. 2013. The Problem of Formal Analysis of the Representations of the Holocaust: Georges Didi-Huberman's Images in Spite of All and Harun Farocki's Respite. Teksty Drugie vol. 14, no. 2: 182-192.

Marks, Laura U. 2000. The Skin of the Film: Intercultural Cinema, Embodiment, and the Senses. Durham and London: Duke University Press.

Merleau-Ponty, Maurice. 2002 [1945]. The Phenomenology of Perception. London and New York: Routledge.

Mitchell, W. J. T. 1994. Picture Theory: Essays on Verbal and Visual Representation. Chicago: Chicago University Press.

Nancy, Jean-Luc. 2000. Le regard du portrait. [The Gaze of the Portrait], Paris: Galilée.

Noys, Benjamin. 2000. Georges Battaile. A Critical Introduction. London/Stirling Virginia: Pluto Press.

Purgar, Krešimir. 2014. Visual Studies and the Pictorial Turn: Twenty Years Later. Images: Journal for Visual Studies vol. 2, no. 2: 1-10. http://www.visualstudies.com/images/no2/purgar.html. Last accessed: 15. 05. 2017.

Rancière, Jacques. 2009. Do Pictures Really Want to Live? Culture, Theory and Critique vol. 50, no. 2: 123-132.

Taberham, Paul. 2013. Bottom-up Processing, Entoptic Vision and the Innocent Eye in the Work of Stan Brakhage. Manuscript.

Tarnay László. 2015. Learning and Re-learning Haptic Visuality. In Cinema of Sensations, ed. Ágnes Pethő, 43-55. Cambridge: Cambridge Scholars Publishing.

Wollheim, Richard. 1968. Art and its Objects. An Introduction to Aesthetics. New York, Evanstown, London: Harper \& Row. 